\title{
Collocation in English and Arabic: A Contrastive Study
}

\author{
Zainab Kadim Igaab ${ }^{1} \&$ Hanan Abdulhasan ${ }^{1}$ \\ ${ }^{1}$ Department of English, College of Education for Humanities, University of Thiqar, Iraq \\ Correspondence: Zainab Kadim Igaab, Department of English, College of Education for Humanities, University \\ of Thiqar, Iraq.
}

Received: October 9, 2018 Accepted: November 1, 2018 Online Published: November 28, 2018

doi:10.5539/ells.v8n4p89 URL: https://doi.org/10.5539/ells.v8n4p89

\begin{abstract}
The present study is descriptive, contrastive and analytic because it describes collocation for the purpose of finding out the similarities and differences between English and Arabic. It aims at describing and comparing collocation in English and Arabic through identifying its basic linguistic aspects which are syntactic, semantic, pragmatic and textual. This study concludes that collocation exists in English and Arabic as a linguistic phenomenon and the two languages study the term from all its linguistic aspects. However, the way to describe collocation linguistically is different to some extent from one language into another.
\end{abstract}

Keywords: lexicology, collocation, contrastive analysis, English, Arabic

\section{Introduction}

Collocation as a linguistic phenomenon is a problematic issue as Barnbrook et al (2013:3) refers to because of the different ways to study and identify it. In English, there are many approaches to define the term collocation and on the top of these approaches are statistical approach and phraseological or linguistic based approach. On the other hand, collocation in Arabic does not have such an important status in the field of linguistics despite the fact that collocation was firstly mentioned in Arabic linguistics indirectly. The study attempts to answer questions like: What are the syntactic, semantic, pragmatic and textual aspects of collocation that are expected to be found in English and Arabic? What are the differences and similarities between the two languages in terms of collocation? And how do the two languages differentiate between collocation and other types of fixed expressions? The aim of this study is to describe, analyse, and then compare collocation in English and Arabic by showing the syntactic, semantic, pragmatic and textual aspects. The study hypothesizes that collocation is found in both English and Arabic; the two languages study collocation from all its linguistic aspects as well as the two languages distinguish between collocation and other types of fixed expressions. The procedure of investigation in carrying out this study involves studying collocation in English, then in Arabic followed by a comparison made between both languages.

\section{Literature Review}

\subsection{Definitions of Collocation in English and Arabic}

Collocation is defined on different bases in the two languages. In English, the basis to define collocation is the given approach in which the linguist is concerned with (Seretan, 2011, p. 10). There are two main approaches to define collocation: statistical and linguistic.

The statistical approach can also be named as the corpus-based approach which defines collocation in terms of co-occurrences without taking into consideration the different aspects of restrictions on the collocated words. In contrast to this approach, the linguistic approach is mainly concerned with the linguistic aspects of collocation which are syntactic, semantic, pragmatic and textual (Nesselhauf, 2005, pp. 11-14). Collocation can be defined in terms of different linguistic levels. Syntactically, it is a sequence of syntactically acceptable combination of words (Cruse, 2006, p. 27). While semantically, collocation is defined as a fixed expression that has one semantic unit (Van der wooden, 1997, p. 5). It also has a very important status in the study of the cohesion of the text and thus, it is defined as one of the important components that make the text more cohesive through the semantic link between its words like the relation between (boy) and (girl) (Halliday \& Hasan, 1976, pp. 284-285). 
On the other hand, collocation (Al-talazum, Al-MuSaHaba, Al-?iqtiran, Al-taDham, Al-Rasf, Al-tawarid) is defined differently in Arabic on the basis of lexical and contextual based-approaches.

Linguists, philologists and lexicologists are divided into two groups. The first group follows the lexical-based approach to collocation. This group is basically concerned with the lexical restrictions on the combination of words, that is to say, words are not free to come with whatever words in the language. The lexical-based collocation is studied by Al-JaHiDh, Sibawayeh, Al-Askary, Ibn Faris, AL-Jerjany and Al-Tha9aluby who studied collocation by listing lists of correct collocated words in the language but they did not give an abstract theoretical study to collocation since they are concerned with giving practical examples of collocated words, for example, the lexical items that are used to combine together in the everyday life like (aSSalah wazakah) (prayer and alms), (ajjaw9 wal-khawf) (hunger and fear), (aljjanatu wannar) (heaven and hell), (al-muhajiriin wal-anSar) (migrants and advocate) and (ajjin wal-inis) (jinn and humans) (Al-JaHiDh, 2003, p. 20).

The contextual-based collocation is a different approach and affected by the contextual view of Firth on collocation in which every word has a meaning when it comes with a particular collocation. The well-known followers of this approach are Abu Al-Faraj, Abdulaziz, Omar and Hassan. They consider collocation as a linguistic context that has a major role to determine the word meaning and they list lots of examples to clarify their idea. Ahmed Mukhtar Omar and Manquur abduljaliil point out that the meaning of a word is determined through different linguistic contexts in which it occurs so that the Context is a preliminary stage for the lexicographers to set an analytical approach for the study of the meaning of words (Al-Amiry, 2013, p. 14). The context-based approach has the following features:

1) It is not concerned with any type of context but the linguistic one.

2) It focuses on the syntactic and collocational aspects of the contexts of words.

3) The sentence does not have a meaning unless it is morphologically, collocationally and syntactically correct (ibid-19).

\subsection{Collocation as Lexis- Grammar Relation in English and Arabic}

In English, collocation is considered as the relation between grammar and lexis because it is difficult to make any kind of separation between the two. Lexis and grammar complete each other and collocation occurs at the mid between the two (Seretan, 2011, p. 21). The term Pattern Grammar is used to show the relation between grammar and lexis because it is mainly concerned with the words that typically come together as well as the grammatical pattern of them ( $\mathrm{Lu}, 2017$, p. 18). Colligation is used to refer to the grammatical structure of collocated words, that is to say, it is not the words that usually come together but the syntactic structures as well. For instance, there are some nouns which are preceded by a personal pronoun rather than an article like examples No. (1) and (2):

(1) Pass my/your driving test. (2) It is my/your/our responsibility to... (Lewis, 2000, p. 237).

Syntactically, collocation is divided into two types: lexical and grammatical. Grammatical collocations consist of the dominant words like verbs, nouns, adverbs or adjectives followed by functional words like prepositions or particles (Benson, 1985, p. 6). The major types of grammatical collocations are:
a) noun + preposition
an attempt to
b) noun +that clause
an agreement that should represent us
c) preposition+ noun
by accident
d) adjective+ preposition
angry at
e) adjective+ to infinitive
ready to
f) verb + object + object
send his brother the book.
g) verb+ object+ to + phrase
send the book to his brother.
h) verb+ preposition
adhere to
i) verb + object + infinitive
heard them leave (Herbst \& Klotz, 2009, p. 236).

On the other hand, Lexical collocations consist of two equal lexical categories like a noun followed by an adjective or a verb followed by a noun (Cruse, 1998, p. 60). The major types of lexical collocations are:
a) verb+ noun
compose music.
b) adverb+ adjective
deeply absorbed. 

c) adjective+ noun
d) noun + verb
e) noun + noun
f) verb+ adverb

\author{
weak tea \\ alarms go off. \\ a herd of buffalo. \\ appreciate sincerely (Herbst \& Klots, 2009, p. 236).
}

The syntactic constructions of the collocated words have different degrees of restrictions that are divided into flexible which means that the two collocated words can come in any type of syntactic structure like (break somebody's heart); regular with certain constraints means that there are some collocated words that are more fixed than the flexible and less fixed than the irregular like (to drop a brick); and the irregular collocation consists of the collocated words that are fixed in terms of syntactic structure, as in (to go on better) (Carter, 1998, p. 71).

In Arabic, the division of collocation is syntactically very complex and open-ended. The syntax of collocated words has a very important position in grammar. Grammarians use (al-qubiH Al- NaHawey) (grammatical ugliness) to refer to the words that are semantically acceptable but syntactically not (Al-Barkawy, 1991, p. 240), for example:

(3) *key zaydan y?teeka) (To make Zaid come to you).

(4)*qad zaidan ra?yta. (You might see Zaid).

The two sentences carry a meaning but the meaning is not complete because of the ungrammaticality among the elements of the sentences (Qanbar, 1960, p. 26). Collocation has a very strong relation with syntax because the words that come together should syntactically be correct since collocation is not merely a combination of lexical items.

Grammarians make a division between (AttaDham Al-mi9jamy) collocation and (AttaDham al-naHawy) colligation. Colligation is the relation between the syntactic elements while collocation is the relation between the follower and the followed words (Al-Najar, 2006, pp. 105-108). There is also another distinction which is made between (Attalazum) collocation and (attanafur) Disagreement. The former deals with the syntactic components that are used to go together like the topic and the comment while the latter is the opposite of collocation. It is used when there is a contradiction between the syntactic units of words that collocate together, for example, the particle should not be followed by another one (ibid).

Another distinction is made between (Attalazum Al-Mudamaj) Incorporated collocation and (Attalazum Al-Munfasil) disjunct collocation. The former refers to the collocated words that are close to each other without any intervention between them like (Aljar wal-Majruur) (Prepositional Phrase), (Al-MuDhaf wal-MuDhaf Ilyahi) (Genitive), (Al-fi9l wal-fa9il) (Subject and Verb) and (AlSifa wal-MawSuuf) (Adjectival Phrase). The most important feature of this kind of collocation is that the collocated words are considered as having one grammatical value. The latter refers to the collocated words that are not close to each other because there are some lexical items between them:

(5) Zaidun allaDi ja?a mina assafari mujtahidun.

Zaid who came from the travel is a hard worker.

(Zaidun) is the topic and (mujtahidun) is the comment. The four words between (Zaidun) and (mujtahidun) do not influence the syntactic relation between the topic and comment (Muhammed, 2010, p. 277).

Collocation is also divided into general standard collocation and specific standard collocation. General standard collocation refers to the general characteristics that are figured out when words come together (ibid-278). It is divided into: (qariina lafDhiyeh) (Syntactic function), (al-Mutabaqa) (Concord), (ADikir) (Mention) and (Al-HaDif) (Ellipsis). Syntactic function refers to the syntactic role of words that is determined through its relation with other syntactic words like subject and object (Hassan, 1979, p. 209). Syntactic function is divided into stable and unstable. The former refers to the position of the syntactic element that is hard or impossible to change its position and the change of its position will lead to the violation of the syntactic structure of the sentence as a whole (Ibada, 2001, p. 11) whereas the unstable syntactic function refers to the syntactic element whose the change of its position will not lead to the violation of the syntactic structure of the sentence as a whole (Al-Zamakhshary, 2004, p. 44).

Concord is a linguistic phenomenon which refers to the agreement between the sentence elements (Igaab and Magrood, 2018, p. 288) and it is divided into: (al-Halatu al-i9rabiya) (case) which is nominative, accusative and genitive, (shakhiS) (person) that is the first, second and third, (9adad) (number) which is singular, plural and dual, 
(aljins) (gender) that is feminine and masculine and (atta9yyen) (definiteness): definite and indefinite. Mention refers to the relation between words that are easily figured out by language users like the relation between the words in the adjective phrase (Hassan, 1979, p. 217) while Ellipsis means that the syntactic relation between the collocated words is not omitted but the users of the language can figure those words out through the hidden relation between the two (ibid). Syntactic functions are used to determine the hidden form, for example:

(6) Wa 9indahum qaSiratu al-Tarafai atrabun

(And they have short-haired party).

(ASSafat, 52) (Al-Hilali and Khan, 1984, p. 617).

(qaSiratu) is the syntactic function which refers to (Hur qaSirat) (Al-Husseiny, 2007, p. 114).

On the other hand, Specific standard collocation refers to the specialized characteristics of collocated words, which is divided into quantitative and qualitative collocation. Quantitative collocation is classified into nominal, verbal and prepositional construction. Nominal construction (Attarkiib Al-Ismy) is the construction in which the noun is the head of the collocated words (Shahadat and Al-Dikhiil, 2015, p. 135). It is divided into Genitive (Al-murakab Al-IDhafy), adjectival phrase (Al-Murakab al-WaSfy) and coinjoined noun (Al-Murakab Al-9aTfy). Genitive is the relation between the noun and its possession (FataHallah, 2017, p. 117) like the collocated words (sin al-biluGhi) (puberty). It is divided into:

i. common noun + proper noun:

(7) assadullahi

the lion of Allah.

(Al-Tha9aluby, 1994, p. 21)

ii. noun + article + noun:

(8) baytul 9ankabuuti

the house of spider.

(Omar, 2008, p. 267).

iii. $\mathrm{Du}+$ noun

(9) Du lawnayn

It has two colours.

(Al-Hadady, 1972, p. 277).

iv. The use of (kul) in the fixed expressions:

(10) kul shat birjliha mu9alaqatun

Every cow is hung by its leg (Omar, 2008, p. 1251).

An adjectival phrase is the relation between the noun and the adjective that describes it for the purpose of description, emphasis and substitution (Shahadat \& Al-Dikhiil, 2015, p. 137) like (al-Harbu al-baridatu) (cold war). A conjoined noun is the relation between nouns that are related by (and) like:

(11) waqafa Omaru wa zaidu

(Zaid and Omar stood.) (Al-Jerjany, 1983, p. 151).

A verbal construction begins with a verb which is a kind of construction which is called (al-murakab al-isnady) (juxtaposed construction) in which one syntactic element is based on the other like the example No. (12):

(12) InqaDha al-?amru

It is over.

(Inqadha) is the verb which comes before the noun (al-?amru) (Shahadat \& AL-Dikhiil, 2015, p. 135). A prepositional construction consists of a preposition plus all types of word classes like:

(13)fi kanafi Allahi

In the hands of Allah (ibid-137).

Qualitative collocation is divided into fixed syntactic structure and semi-fixed syntactic structure. The former refers to the collocated words that have a fixed syntactic construction like the construction of blame, 
interrogation, preference, warning and praise while the latter refers to the habitual constructions of some collocated words. The construction becomes regular by the language users like (ja?a min) (he came from) and (Dahaba ila) (he went to).

Collocation can syntactically be divided into (Al-IkhtiSaS) Specialization, (Al-FaSl) Negative Collocation and (Al-I9turaDh) Collocational Intervention. Specialization means that there are some specific particles that come with specific ones: (Inna wa akhawatuha) (inna and its sisters). A negative construction refers to the disagreement between the collocated words such as (kila wa kilta), which do not come with non- definite, singular or plural nouns. Collocational intervention refers to the intervention between the collocated words:

(14) YusabiHu lilahi ma fi al-samawati wama fi al-arDhi

Whatsoever in the heavens and whatsoever is on the earth glorifies

(Al-jum9a, 1) (Al-Hilali \& Khan, 1984, p. 763)

The word (lilahi) comes between the verb (yusabiHu) and the subject (mafi al-samawati wama fi al-arDhi). The reason for this intervention is stylistic which is to restrict the creation of the sky and earth to Allah. Al-i9tiraDh means the intervention in terms of sentences (Al-Najar, 2006, pp. 108-129)

In spite of the different syntactic constructions of collocation in the two languages, there are no general fixed syntactic rules for collocation. The collocated words come in whatever syntactic structures they might come.

\subsection{Semantic and Pragmatic Aspects of Collocation in English and Arabic}

\subsubsection{Restrictions in English and Arabic}

In English, there should be a semantic relationship which holds between the words of the sentences, otherwise, that will lead to a contradiction between the words of sentences (Robins, 1981, p. 54). There are some restrictions on word combination which are semantic. The restriction is divided into selectional and collocational. A selectional restriction is semantic in which the meaning of a word determines the other words with which it comes so that the semantic features of a word restrict the number of words with which it can come, for example:

(15) *The stream danced.

The example No. (15) is semantically unacceptable because the subject of the verb (danced) should be animate (Carter, 1998, pp. 56-57).

On the other hand, a collocational restriction is haphazard, that is to say, there is no semantic reason for the restriction on words (Croft \& Cruse, 2004, p. 249). The restriction is basically lexical, so the collocated words might semantically be acceptable but collocationally not:

(16) Pay a visit (acceptable)

$(17)^{*}$ make a visit (unacceptable).

Another example is (addled) and (rancid). Although these two words have the meaning of (stale) and (rotten), the word (addle) comes with (egg) and (rancid) comes with (butter) only (Baker, 1992, p. 47).

The violation of the selection restriction leads to inappropriateness while violating the collocational restriction leads to senseless sentences (Collinge, 1990, p. 99). Palmer (1981, p. 79) sums up the collocational restrictions into three types: the first type basically depends on the meaning as in the inappropriate collocation of (green cow). The second type is the restriction which is based on the range which means the words should share some semantic features and not be contradicted as in the inappropriate collocation of (pretty boy). The third is the restriction which is merely collocational as in the collocation between (blond) and (hair).

Collocational restrictions can be divided in terms of their degree into:

- Unrestricted collocation is the collocation which contains the lexical items that are free to be combined with a wide range of words as in the word (take). It can collocate with a large number of words like: (take a look), (take a holiday), (take a rest), (take a letter), (take time), (take notice), (take a walk), etc.

- Semi-restricted collocation includes the lexical items whose substitution is more determined like: (harbor doubt/grudges/uncertainty/suspicion), etc.

- Familiar collocation includes the lexical items that keep a regular company. They are considered as a type of fixed expressions, as in: (innocent bystander), (unrequited love), (unmitigated disaster) and (readily admit). 
- Restricted collocation contains the lexical items whose relation is more fixed and closed, as in: (stark naked) and (pitch black) (Carter, 1998, pp. 70-71).

Sometimes, the language users are not intended to follow the collocational restriction for the purpose of achieving the marked collocation which is used mostly in the literary style to attract people's attention, for example:

(18) Some tout at the book fair wanted me to take UK rights in a book on glasnost and the crisis of peace. Essays by past and present hawks, reappraisals of strategy. Could real peace break out after all?

Users of language are used to combine (peace) with (prevails) and not (breaks out). The use of unmarked collocation in this situation is to capture people's attention about the temporariness of war and its undesirability in contrast with peace which is more desirable (Baker, 1992, p. 51).

In Arabic, Restrictions means the constraints on the word combination because the words do not come together randomly but in fact there are some restrictions on their combination. They use the term (qawa?id Intiqa?iya) Selective Rules to refer to the selection restriction used by Chomsky which is basically concerned with the semantic relation that holds between words (Versteegh, 2011, p. 434). Collocation has a very important role to make the language appropriate. Grammarians use the term (al-kalam al-kaDib) Lying Speech to refer to the speech that does not include the correct collocation (Sibawayeh, 1988, p. 26). Collocational restriction is divided into:

- The restriction which is based on the meaning of words that come together, for example, (baqaratun Safra? un) (yellow cow).

- The restriction which is based on the range of words that share some semantic features, for example, (allaylu wannaharu) (day and night). They have a semantic feature of opposition.

- The restriction which is haphazard is not based on any systemic rule, for example, (sha9run ashqarun) (blond hair) but not (*baytun ashqarun) (blond house) (Al-Hilwa, 2012, p. 66).

Collocation is also divided in terms of the degree of the restrictions into:

- Open collocation: It has a feature of being freely combinable and the meaning of the whole can be determined from the meaning of the parts: (bada?at al-ma9rakatu) (the battle began).

- Restricted collocation: It is more restricted than open collocation. It refers to the words that regularly come together but they have non-idiomatic meaning: (Harbun Dharuusun) ( ferocious war) and (jarimatun nakra? un) (heinous crime)

- Bound collocation: It is the more restricted than restricted collocation and it occurs between idioms and collocation, in which one of the components is based on the other like (aTraqa arra?sa) (he lowered his head).

- Idiom: It is the most restricted type of collocation that refers to the combination of words that have a non-literal meaning in the sense that the meaning of the whole cannot be predicted from the meaning of the parts like (Harbun baridatun) (cold war). The meaning of (cold war) does not refer to the war that is not hot but to the intense of political, economic and military competition among nations (Brashi, 2005, p. 43).

\subsubsection{Collocation and Other Types of Fixed Expressions in English and Arabic}

In English, there is much emphasis on the difference that occurs between collocation and other types of word combinations like idioms, free combinations, transitional combinations, compounds and clichés.

An Idiom is different from a collocation because the meaning of the idiom is not compositional, that is to say, the meaning of the whole cannot be predicted from the meaning of the parts like:

(19) to have cold feet. The meaning of this phrase cannot be taken literally as (frozen feet) or (chilly feet) but it means idiomatically (to be afraid of) (Carter, 1998, p. 65). Another view shows that the meaning of the collocated words is very difficult to be predicted from their constituent parts like an idiom (Seretan, 2011, p. 23). The basic features of the collocation are non-compositional, non-modifiability and non-substitutability (Manning and Schutze, 1999, pp. 172-173). A collocation is considered by some linguists as a cover term to include all types of fixed expressions in the language (Van der wooden, 1997, p. 9).

A Free Combination refers to the words that have a wide range of words to come with. Free combinations refer to the words that are free to combine with different words in the language, for example, (murder) can come with many verbs like (analyze), (describe), (discuss) and (condemn). These verbs combine with different nouns like (accident), (adventure), (discovery), (event), (experience), (idea), etc. Collocated words, on the other hand, are 
not freely combined like free combinations but they are fixed to some extent, for example, (commit murder). The word (commit) cannot be replaced by any lexical item except (perpetrate) in this situation (Lu, 2017, p. 14).

A Transitional Combination refers to the combination of words that are less fixed than an idiom and more frozen than a collocation, for example, (to foot the bill), (to catch one's breath ) and (all dressed up) (Van der wooden, 1997, p. 8). Compounds refer to two or more words that come together more frequently than the collocated words (ibid).

Clichés refer to a group of words whose meaning is completely compositional so that the meaning of the whole can be predicted from the meaning of parts. This group of words is stored in the mind of the language users. Clichés are less restricted than collocations, for example:

(20) I have made my position absolutely clear.

In Arabic, there is much emphasis on the difference between a collocation and an idiom, a free combination, a contextual expression, a free combination, a co-occurrence and an acronym.

An idiom refers to a group of words that has a meaning which cannot be predicted from its constituent parts which means it is the opposite of the collocation (Omar, 1998, p. 75). However, a collocation is similar to an idiom in that both of them compose of words that come together more often and the linguistic environment has its influence on both of them. A collocation is different from an idiom in a way that an idiom can compose of one word while a collocation should compose of more than one word and secondly, an idiom has a non- literal meaning while a collocation has literal and non-literal meanings (Al-Husseiny, 2007, p. 98).

Contextual Expressions refer to the words whose individual meaning is different from their contextual meaning (9ukasha, 2005, p. 188). Unlike collocations, contextual expressions put much emphasis on the context in which they are used and how the context plays a very important role to specify their meaning (Al-Qasimy, 2003, p. 103). Examples of the contextual expressions are:

(21) alqamahu al-darisa

He taught him the lesson.

(22) alqama munafisahu Hajaran

He stops his competitor by a stone

(23) ja9alaho luqmatun sa?iGha

Hhe made him a tasty bite

Another example is luqmat ul-9aysh (For a living).The node (laqama) has many different meanings in accordance with the words with which it comes (Omar, 2008, pp. 20-29). A free combination refers to the words that are not so much restricted like a collocation. The words in the free combination are free to come with a wide number of words in the language (Omar, 2009, p. 77).

A Co-occurrence refers to the words that have one rhythm in the language like (ShayTan layTan). A collocation is different from a co-occurrence because it does not matter for it to have words of the same rhythm (Al-Husseiny, 2007, p. 124). An acronym refers to the combination of initial letters of two or more words to be produced, for example, (abshamy) is composed of (abd) (slave) and (shams) (sun). It can be described as a type of a collocation because some linguists define it in terms of the co-occurrence of two words (ibid, pp. 128-129).

\subsubsection{Meaning by Collocation}

In English, the term Meaning by Collocation means the meaning of a word that is determined by the words with which it comes. A collocation has an important status to determine the word meaning like:

(24) I cut my foot.

(25) I cut the grass.

In example No. (24), the action of cutting happens unintentionally or not deliberately in contrast with example No. (25) in which the speaker intentionally cuts the grass (Riemer, 2010, p. 57).

A context is divided into two types: collocational and situational. A collocational context is the linguistic context which refers to the words around the word in question and has an important role to determine its meaning. A situational context is also called the physical context which refers to the time and place in which the word is used. Linguists show the different meanings of words through putting them in different collocations (Storjohann, 2010, p. 120). The main use of collocation in the language is to determine the synonymous and homonymous words in the language. 
In Arabic, a collocation is also used to determine the word meaning and it is mostly used in the Holy Quran to give different meanings of a word because of its uses in different contexts, for example:

(26) Qara?tu alfaSla alkhamisa mina al-kitabi.

I read the fifth chapter of the book.

(27) ?inna arrabi9a huwa ajmala faSlin min fuSuuli assanati.

Spring is the most beautiful season of the year.

(28) innana al?ana fi alfaSli aldirasy al?awala mina al-sanati.

We are now in the first course of the year.

(29) Shahadna alfaSla althani mina al-masraHiyati.

We watched the second part of the play.

(30) Lam yastalim qarara alfaSli mina al-9amali.

He did not receive his displace in the work.

(31) ?nnahu liqawlun faSl.

It is a right speech.

Everyone can notice the different meanings of the word (faSl) due to the different contexts in which it occurs. It can also be noted that the single word (faSl) has different translations because of different meanings (Al-khuly, 2001, p. 69). It is also used to determine the synonymous and homonymous words in the language.

\subsection{Textual Aspect of Collocation in English and Arabic}

In English, Cohesion is a semantic unit referring to the text which is described as having a semantic unit (Halliday and Hasan, 1976, p. 4). It is divided into grammatical, lexico-grammatical and lexical cohesion. Grammatical cohesion consists of ellipsis, reference and substitution. Lexico-grammatical consists of conjunction and lexical collocation consists of reiteration and collocation (Khodareza \& Ashour, 2016, p. 18) which is the basic concern of the present study.

Collocation has a very important role in making the text more cohesive through the semantic relations that hold between the words coming together. The semantic relations that hold between the collocated words are divided into:

- ordered set is the most systemic type of collocation relation. It refers to a set of words that are ordered systematically like colours, numbers, months, days of week: September, January, Monday, Sunday, etc.

- activity related collocation is the relation that is difficult to define. This kind of relation is not systemic. It is based on the associations that hold between the lexical items in terms of activity, for example, the relation between (cyphers) and (decode) (meals) and (eat), (driving) and (car). The relation between these items is based on the activity.

- elaborative collocation is the most problematic type of collocation relation and it is difficult to be defined or even described:

(32) At the beginning of Michaelmas term 1955. Sylvias' first year at Cambridge. I had walked into Mill Lan lecture room a few minutes early

The relation is not totally haphazard which is supported by the concept of Frame Theory. Frame theory is based on the idea that the meaning of a single word cannot be understood unless there is an access to the essential knowledge that is related to that word. Concerning the example No. (32), the word (Cambridge) can be interpreted within the frame (Tanskanen, 2006, pp. 60-63).

A Field is a term which is used to refer to the words that are used in a given topic or activity, for example, (flight), (take-off), (runway), (check in), etc. The users of the language use specific vocabulary in a specific situation. Sometimes, the meaning of a lexical item is different according to the topic of the situation like (wing) which carries different meanings when it comes with (air transport) and (theatrical parlance) (Carter, 1998: 54). The relation between these words is paradigmatic not syntagmatic like the relation between colours or days of the week. Moreover, the words are incompatible which means that the occurrence of a lexical item of a particular field prevents other lexical items to occur:

(33) This is a red hat. 
So (red) is incompatible with other colours like (green).

(34)*this is a green hat (Palmer, 1981, pp. 68-69). A Set refers to the group of words that are related semantically to make the text more cohesive. The words (stag), (geometry) and (innocent) are unlikely to occur together in a text because there is a kind of semantic relationship between the two. On the other hand, the words (thirst), (beer) and (drink) have no chance to come together since there is no sign of relation between them in terms of meaning (Carter, 1998, p. 54).

In Arabic, cohesion has a very important status in the study of text and it is one of the main elements in the field of rhetoric (Abdullah, 2018, pp. 48-49). Cohesion is divided into grammatical and lexical. Grammatical cohesion is divided into reference, substitution, ellipsis and conjunction. Lexical cohesion is divided into reiteration and collocation. Collocation is the syntagmatic relation between the lexical items that share some semantic features between the items.

There are two types of art that has an important status to achieve the aesthetic function in writing a text. Those types are (Al-muTabaqa) coincidence and (Al-naDhiir) comparison. The former refers to the semantic relation that holds between the collocated words while the latter refers to the words that are not related semantically (Abdul-Majeed, 1998, pp. 109-117).

The semantic relations between the collocated words are divided into:

$\diamond \quad$ an opposition which refers to the words that are opposite to each other in terms of meaning. Opposition is used to attract people's attention such as what is mentioned in surat Al-Shu9araa in which the relation between (alsamawaat wal-?arDh) (heavens and earth) has a cohesive effect on the text:

(35) Qala rabu assamawati wal ?arDh wa ma baynahoma in kintom moqiniin.

The Lord of the heavens and earth and all that is between them, if you seek to be convinced with certainty (Ashu9araa. 24). (Al-Hilali \& Khan, 1984, p. 490; Abdullah, 2018, p. 167).

$\diamond$ the relation by a given topic is the relation that holds between the words that are linked semantically (Al-Hilwa, 2012, p. 77). It is the opposite of opposition because it is not concerned with the differences but the similarities between word meanings. The relation by a given topic has a very important position to make the text more cohesive. For example, (A19azizu arrahiimu) (all-mighty and the most merciful):

(36) Wa? rabika lahwa al-9azizu arraHiimu.

And verily, your Lord, He is truly the all-mighty, the most Merciful. (Ashu9araa: 9). (Al-Hilali \& Khan, 1984, p. 489; Abdullah, 2018, p. 176).

$\diamond \quad$ a whole-part relation which technically means hyponymy. It is the relation between the words that are used in our everyday reality.

$\diamond \quad$ a relation by mutual inclusion which refers to the relation that holds between a specific component and a general one; This relation is technically called (inclusion) (Al-Hilwa, 2012, p. 75).

$\diamond \quad$ a part -part relation which refers to the relation between words that have subdivisions:

(37) sayaDDakeru man yakhsha

The reminder will be received by him who fears (Allah).

(al-A9la: 10) (Al-Hilali and Khan, 1984, p. 834 and Al-Blooshy, 1998, p. 67).

$\diamond \quad$ the relation between subordinated words which have one superordinate like the relation between (chair) and (table) which are all related to the furniture (KhuTaby, 2006, p. 25).

\section{Method}

The following procedures of investigation in achieving this study are adopted:

The first step is giving a full description and analysis of collocation in English and Arabic by showing its definitions, the basic linguistic aspects which are syntactic, semantic, pragmatic and textual as well as making a distinction between collocation and other types of fixed expressions. The second step is illustrating the similarities and differences between the two languages in terms of collocation. Finally, the third step is translating every Arabic word in the Arabic sections into English and then all the examples are transliterated by using the Arabic phonemic symbols. 


\section{Results}

The study proves that collocation is a linguistic phenomenon which exists in English and Arabic and the two languages study collocation from all its linguistic aspects that are syntactic, semantic, pragmatic and textual. So, the first and second hypotheses are accepted. However, the way to study collocation linguistically is to some extent different from one language into another and this supports the third hypothesis of this study. The two languages consider collocation as a problematic issue and so they are concerned with the distinction between collocation and other types of word combinations like idioms, free combinations, contextual expressions, etc. Such a result verifies the fourth hypothesis.

\section{Conclusions}

\subsection{Similarities}

The similarities of collocation between English and Arabic are as follows:

1) Collocation is a linguistic phenomenon that exists in Arabic and English and this agrees with the first hypothesis of this study.

2) Collocation is studied by linguists from all its linguistic aspects which are syntactic, semantic, pragmatic and textual. Those two points ( 1 and 2) answer the research questions.

3) Collocation is generally defined as the habitual co-occurrence of two or more words in the language.

4) There is no one definition for a collocation because there is a number of different studies and approaches to collocation. Collocation can be described in different fields of studies. Thus, the definition of collocation in syntax is different from its definition in semantics and the like.

5) Collocation occurs at the intersection between grammar and lexis. It is true that the collocation is a combination of more than two words but these two words should syntactically be acceptable.

6) Colligation is the term which is used to refer to the syntactic aspects of the collocated words. So, if a collocation is a typical co-occurrence of words, colligation will be a typical co-occurrence of syntactic elements like the subject which should be followed by a verb.

7) It is difficult to study collocation away from grammar because the words that come together are automatically related by grammar.

8) Some linguists find out that collocation is independent of grammar because the words that are considered as collocated words can come in whatever syntactic structure is. It is not necessary to have fixed syntactic rules.

9) Collocation is arranged from more syntactically flexible combination of words to more syntactically fixed combination of words. Some collocated words are fixed in terms of syntax and some are not.

10) There are no general and reliable syntactic rules for collocated words but the two languages set some major types of the collocated words.

11) The words that come together should semantically be related, so they are not merely a combination of words but there should be a semantic link between them.

12) There are some semantic restrictions on the word combinations which are determined through the semantic features of the collocated words. There should be an agreement in terms of semantics between or among the collocated words. These restrictions are technically called selectional.

13) Collocational restriction is random and is not based on any systemic rule or principle.

14) There are some attempts to divide the collocational restrictions into:

$>$ The restrictions based on the meaning.

$>$ The restrictions based on the range.

$>$ The restrictions merely collocational.

15) The collocational restriction is arranged from more into less fixed. Some words are so fixed and they do not come with whatever lexical items are while the others are more flexible.

16) Every word has a range of words to come with. The range is sometimes wide and sometimes restricted.

17) The use of the correct collocation leads to the appropriateness in using the language and not the vice versa. Without collocation, the language will be messy. 
18) A collocation is a type of fixed expressions and it is difficult to make a clear-cut between it and other types of word combination. This point supports the limits of the study.

19) There are some attempts to differentiate between collocation and other types of fixed expressions.

20) A collocation is more fixed than a free combination and less fixed than an idiom. It occurs at the mid between the two.

21) The meaning of the collocated words can be predicted from their constituent parts but sometimes they cannot. So, a collocation can carry literal and non-literal meanings.

22) A collocation is described as the linguistic context of a word. The meaning of a word can be determined by the collocated words with which it can come with.

23) Collocation is used to identify the homonymous and synonymous words in the language through putting the word in question into different linguistic contexts and consequently showing its different meanings.

24) Collocation can be used in the study of the text to refer to the syntagmatic and subsequent relations of the words in the text. This subsequent relation has a very important role in the text.

25) A collocation is a type of lexical cohesion in the language in addition to reiteration.

26) Collocation contributes to make the text more cohesive through the semantic relations of the collocated words.

27) The sematic relation between the collocated words is open-ended, however; the two languages set some of the major ones.

\subsection{Differences}

The differences of collocation between English and Arabic are as follows:

1) Collocation was firstly studied in Arabic without having a technical term and then it is studied elaborately and deeply by English linguists under the name of collocation.

2) Collocation in English has one term while in Arabic has many terms because Arabic is considered as the richest language in using synonyms.

3) The term Collocation is defined in English using the two approaches: statistical and linguistic. The former defines collocation in terms of co-occurrence while the latter defines collocation in terms of the linguistic restriction on the collocated words. On the other hand, Arabic defines collocation from the lexical based and the contextual based approaches. The former refers to the lexical restriction on words combination while the latter refers to collocation as a linguistic context.

4) Arabic grammarians rather than English ones pay much attention to the syntactic relations between the collocated words.

5) In English, the term Collocation is syntactically divided into lexical and grammatical. Lexical collocation is the relation between words from the open system class while grammatical collocation refers to the relation between the word from open class system and another word from close class system. In Arabic, collocation is divided into general standard collocation and specific standard collocation. The former refers to the general characteristics of words when they come together while the latter refers to the specific characteristics of collocated words in terms of syntax.

6) The division of Arabic collocation syntactically is very complex while in English it is not. General standard collocation is divided into syntactic function, concord, mention and ellipsis while specific standard collocation is divided into qualitative and quantitative collocation. The former is divided into fixed syntactic structure and semi-fixed syntactic structure while the latter is divided into nominal, verbal and prepositional construction. In English, there are no such complex divisions.

7) In English, collocation is divided from the viewpoint of syntactic restrictions into flexible, regular with certain constraints and irregular while in Arabic there is no such a division.

8) There is a distinction in Arabic between collocation and disagreement. The former refers to the agreement between or among the collocated words while the latter is the opposite one. There is no focus on the disagreement in terms of syntax in English.

9) In Arabic, there is also a distinction between incorporated collocation and disjunct collocation. The former refers to the collocated words that are close to each other while the latter refers to the words that are far from each other. English is not concerned with the syntactic functions of the collocated words. 
10) English divides restrictions into selectional and collocational while Arabic does not give such a difference. They use collocational restrictions to refer to both selectional and collocational ones.

11) In Arabic, linguists use the selective rule while in English selection restrictions are used.

12) In Arabic, there is a use of the term lying speech to refer to words that are not correct collocationally. There is no such emphasis in English.

13) Collocational restriction is divided in English into unrestricted, semi-restricted, familiar and restricted while in Arabic, it is divided into open collocation, restricted collocation, bound and idiom.

14) Collocation in Arabic is used as the measure to determine whether the words are suitable or not while in English there is no such emphasis.

15) In English, there is the use of marked collocation which refers to the violation of the collocational restriction for a purpose in the mind of the language users while in Arabic there is no such a term or a reference to it.

16) In English, there is too much emphasis on the collocational range which refers to the number of words in which a word can be used whereas in Arabic, there is not.

17) English differentiates collocations from idioms, compounds, free combinations, clichés and transitional combinations while Arabic differentiates collocations from idioms, free combinations, contextual expressions, acronyms and co-occurrences.

18) In English, collocation can be used to refer to all different types of fixed expressions while in Arabic there is no such a general statement.

19) English divides contexts into situational and collocational. Collocation is defined in this respect as a linguistic context while Arabic does not have such a difference between these two different types of contexts.

20) Cohesion is divided in English into grammatical, lexico-grammatical and lexical while in Arabic it is divided into grammatical and lexical only.

21) English puts too much emphasis on the fields and sets while Arabic does not. These two terms are basically used in making the text more cohesive when writing a text through using words that are related semantically.

22) English divides the semantic relation between collocated words into ordered set, activity related collocation and elaborated collocation while Arabic into: opposition, the relation by a given topic, whole-part relation, a relation by mutual inclusion, part-part relation and the relation between subordinated words.

\section{Recommendations for Future Work}

The researcher sets some recommendations.

There should be an emphasis on the study of collocated words in teaching English because this will lead the students to use the language appropriately like native speakers. There should also be a separation between Arabic collocation and English collocation in teaching the language because every language has its own collocation which is completely different from other languages.

In addition, there should be much emphasis in the study of linguistics on the study of lexis as a linguistic level according to Halliday's Systemic Functional Grammar. Finally, course designers are advised to provide an explanation of syntactic, semantic, pragmatic and textual aspects of collocation because there is a serious lack of them.

\section{References}

Abdullah, A. (2018). Effects of Lexical Link in Qura'n Discoursal Cohesion in Al-Shu9araa Sura. Unpublished MA thesis. Wahraan: University of Wahraan.

Abdul-Majeed, J. (1998). Al-badii fi Al-balaGha al-9arabeya wa Al-lisaneyat Al-naSeya. Cairo: The Egyptian Public Department.

Al-Amiry, F. (2013). Collocation and its Semantic Effect: A study in Nahij Al-BalaGha Book. UnPublished PhD Thesis. Najaf: AL-Kufa University.

Al-Barkawey, A. (1991). The Meaning of Context between Traditional and Modern Linguistics (1st ed.). Cairo: Dar Al-Manaar. 
Al-Blooshy, A. (2014). Cohesion in Al-Mulk and Al-A9laa Suras: An Analytic Study in Text Linguistics. Arabic Language Magazine on Media, 4.

Al-Hadady, F. (1972). FaiDh Al-Qadiir: ShariH Al-Jami9 AL-SaGhiir (2nd ed.). Beirut: House of knowledge.

Al-Hilali, M., \& Khan, M. (1984). Translation of the Meaning of the Noble Qura'n in the English Language. Madina: King Fahad Glorious Quran Printing Complex.

Al-Hilwa, N. (2012). Collocation and its Role in the Text Cohesion: Muqaraba NaSiyah in the Articles of Dr. Khalid Naeyf. Islamic Studies Magazine, 14(3).

Al-Husseiny, H. (2007). Collocation and its Semantic Determination on the Holy Book, Quran. Unpublished PhD Thesis. Cairo: Al-Azhar University.

Al-JaHiDh, A. (2003). Al-Bayan Waltabeyiin. Cairo: The Public Department for Culture Palaces.

Al-Jerjany, A. (1983). Definitions (1st ed.). Cairo: House of Book.

Al-khuli, M. (2001). Semantics. Jordan: Dar al-falah.

Al-Najar, N. (2006). Collocation and Sequence in Grammatical Thought. Sciences of the Language.

Al-Qasimy, A. (2003). The Lexicon between Theory and Practicality. Beirut: Lebanon Library.

Al-Tha9aluby, A. (1994). Thimar Al-Qiluub (1st ed.). Damascus: Dar Al-Basha?ir.

Al-ZamaKhshary, A. (2004). Al-MufSal in Arabic Language. Jordan: Dar Amman.

Baker, M. (1992). In Other Words: A Course book on Translation. London: Routledge.

Barnbrook, G., Mason, O, \& Krishnamurthy, R. (2013). Collocations Applications and Implications. New York: Palgrave Macmillan.

Benson, M. (1985). Collocation and idioms. In R. Ilson (Ed.), Dictionaries, Lexicography and Language Learning. Oxford: The British Council, pp. 61-68.

Betti, M. J. (2007). Jokes in Iraq: A Study of Coherence and Cohesion. Journal of the College of Education-University of Wassit, 1(1).

Brashi, A. (2005). Arabic Collocation: Implication for Translation. Unpublished PhD thesis. Sydney: University of Western Sydney.

Carter, R. (1998). Vocabulary: Applied linguistic Perspective. London: Routledge. https://doi.org/10.4324/9780203270110

Colling, N. E. (1990). An Encyclopedia of Language. London: Routledge.

Croft, W., \& Cruse, D. A. (2004). Cognitive Linguistics. Cambridge: CUP. https://doi.org/10.1017/CBO9780511803864

Cruse, D. A. (1986). Lexical Semantics. New York: CUP.

Cruse, D. A. (2006). A Glossary of Semantics and Pragmatics. Edinburgh: Edinburgh university press.

FataHallah, A. (2017). Collocation in Contemporary Arabic Dictionary. Unpublished MA Thesis. Baghdad: Baghdad University.

Halliday, M., \& Hasan, R. (1976). Cohesion in English. London: Longman.

Hassan, T. (1979). Arabic Language: Its meaning and Structure (2nd ed.). Cairo: The Egyptian Public Department for Book.

Herbst, T., \& Klotz, T. (2009). Syntagmatic and phraseological Dictionaries. In A. Cowie (Ed.), The Oxford History of English Lexicology (vol. 1, pp. 219-259). Oxford: OUP.

Ibada, M. (2001). Arabic Sentence: Its constructions, Types and Analysis (3rd ed.). Cairo: Library of Arts.

Iggab, Z. K., \& Magrood, S. (2018). Concord in English and Arabic: A Contrastive Study. International Journal of English Linguistics, 8, 288-297. https://doi.org/10.5539/ijel.v8n2p288

Khodareza \& Ashori, S. (2016). An Analysis of Cohesive Devices and Collocation in English Textbook and Teachers' Attention to them. UnPublished MA Thesis. Azad: Azad University Press.

Khutaby, M. (1991). Text Linguistics. Beirut: The Arabic Cultural Centre. 
Lewis, M. (2000). Teaching Collocations: Further Development in the Lexical Approach. Language Teaching Publication.

Lu, Y. (2017). A Corpus Study of Collocation in Chinese. London: Routledge.

Manning, C. D., \& Schutze, H. (1999). Foundation Of Statistical Natural Language Processing. UnPublished MA Thesis. Cambridge: MIT Press Cambridge.

Muhammed, J. (2010). The Phenomenon of Grammatical Collocation and the Method of the Syntactic Thinking. Dubai: The College of Islamic Studies.

Nesselhauf, N. (2005). Collocation in Learner Corpus. Amsterdam: John Benjamins Publishing Company. https://doi.org/10.1075/scl.14

Omar, A. (2008). Industry of Modern Lexicon (1st ed.). Cairo: World of Books.

Omar, A. (2009). Industry of Modern Lexicon (3rd ed.). Cairo: World of Books.

Palmer, F. R. (1981). Semantics. Cambridge: CUP.

Qanbar, I. (1960). Sibawayeh's Book (1st ed.). Beirut: Dar AL-Jiil.

Riemer, N. (2010). Introducing Semantics. Cambridge: CUP. https://doi.org/10.1017/CBO9780511808883

Robins, R. (1982). General Linguistics: An Introduction. New York: Longman Books.

SaHadaat, M., \& Al-Dikhiil, M. (2015). The Meaning of Idioms. International Journal of Islamic Studies, 2(2).

Sibawayeh, A. (1988). The Book (3rd ed.). Cairo: Al-Khanjey Library.

Storjohann, P. (Ed.). (2010). Lexical-semantic Relations: Theoretical and Practical Perspectives. Amsterdam: John Benjamins Publishing Company. https://doi.org/10.1075/lis.28

Tankskanen, S. (2006). Collaborating towards Coherence. Amsterdam: John Publishing Company. https://doi.org/10.1075/pbns.146

Van der wooden, T. (1997). Negative Context: Collocation Polarity and Multiple Negation. London: Routledge.

Versteegh, K. (2011). Encyclopedia of Arabic Language and Linguistics. Leiden: Brill.

\section{Appendix A.}

\section{A List of the Symbols of Arabic Phonemes}

\begin{tabular}{|c|c|c|}
\hline /f/ & /fiil// & an elephant \\
\hline /th/ & /tha9lab/ & fox \\
\hline /D/ & /Dabha/ & he threw it \\
\hline$/ \mathrm{Dh} /$ & /Dhabut/ & an officer \\
\hline$/ \mathrm{s} /$ & /suug/ & market \\
\hline$/ \mathrm{S} /$ & /Sabur/ & patience \\
\hline $\mid \mathrm{z} /$ & /zraar/ & button \\
\hline$/ \mathrm{sh} /$ & /shmaalak/ & What is wrong with you? \\
\hline$/ \mathrm{kh} /$ & /khubuz/ & bread \\
\hline$/ \mathrm{Gh} /$ & /Ghraab/ & crow \\
\hline$/ \mathrm{h} /$ & /hnaa/ & here \\
\hline$/ \mathrm{H} /$ & /Hariim/ & women \\
\hline$/ \mathrm{b} /$ & /baab/ & door \\
\hline$/ \mathrm{t} /$ & /timman/ & rice \\
\hline$/ \mathrm{T} /$ & /TamaTa/ & tomatoe \\
\hline /d/ & /tdanna/ & be nearby \\
\hline$/ \mathrm{Dh} /$ & /Dhaal/ & staying \\
\hline$/ \mathrm{k} /$ & /ka9ak/ & cake \\
\hline$/ \mathrm{q} /$ & /qadiim/ & old \\
\hline /?/ & /?ams/ & yesterday \\
\hline$/ \mathrm{j} /$ & /jamaal/ & beauty \\
\hline /g/ & /ga9ad/ & he set down \\
\hline$/ \mathrm{m} /$ & /minhu/ & who is it? \\
\hline$/ \mathrm{n} /$ & /nibaH/ & barked \\
\hline$/ 1 /$ & /limna/ & gather us \\
\hline$/ \mathrm{w} /$ & /wayyana/ & with us \\
\hline$/ \mathrm{y} /$ & /yamta/ & when \\
\hline /9/ & /9aali/ & high \\
\hline
\end{tabular}




\begin{tabular}{lll}
\hline$/ \mathrm{r} /$ & $/ \mathrm{ramul} /$ & sand \\
$/ \mathrm{p} /$ & $/ \mathrm{parda} /$ & curtain \\
$/ \mathrm{i} /$ & $/ \mathrm{mi} 9 \mathrm{da} /$ & stomach \\
$/ \mathrm{a} /$ & $/$ saliim/ & healthy \\
$/ \mathrm{aa} /$ & $/$ saalim/ & safe \\
$/ \mathrm{u} /$ & $/ \mathrm{ummii} /$ & my mother \\
$/ \mathrm{uu} /$ & $/ 9 \mathrm{uud} /$ & stick \\
\hline
\end{tabular}

The Arabic symbols are taken from Betti (2007, pp. 409-410) with modifications.

\section{Copyrights}

Copyright for this article is retained by the author, with first publication rights granted to the journal.

This is an open-access article distributed under the terms and conditions of the Creative Commons Attribution license (http://creativecommons.org/licenses/by/4.0/). 